\title{
Baby Monitoring for SIDS Prevention - IoT
}

\author{
Agnes Shiny Rachel, Pavithra M., Gokul kumar R., Lokesh N. S.
}

\begin{abstract}
Sudden Infant Death Syndrome also known as SIDS, is the leading cause of mortality in infants from a month to a year of age. Today's lifestyle is fast-paced. Most of the working parents find a bit of difficulty to manage their work along with their child. So, they leave their baby to the grand-parents of the child. Due to SIDS, the infants have abnormal breathing, body temperature and digestion. In recent years, they use an 'Eulerian magnification' technique to detect the motion of the child. In that, they use a light camera to detect the action of the child and generate an alarm in the cradle. So, we proposed a method to detect the action of the child. We use a motion sensor to detect the motion of the child. During infant's sleep their chest movement due to respiration is detected. When the SIDS occurs, infants would stop breathing. So, the sensor doesn't detect any motion. It immediately sends an SMS to the working parents and generates an alarm in the cradle. Along with this, it also determines the availability of doctor in the nearby hospital or their family child specialist and sends the availability message to their parents and guardians mobile by using cloud algorithm. By this we can reduce the mortality of the child due to SIDS.
\end{abstract}

Keywords: Cloud technology, Raspberry pi, IOT, Video surveillance.

\section{INTRODUCTION}

Sudden Infant Death Syndrome (SIDS) is also called as crib death. It is one of the disastrous disease developed in infants between the age group of one month to one year of age. The exact cause of SIDS disease is not known, even after the autopsy. In 2002, Dror lederman has developed Hidden Markov Model in Infant's cry classification. This method is used to classify the cry of the child. It is based on Continuous density Hidden Markov Model (CD-HMM). The classification of cries is used to determine the different diseases in infants [1]. In 2005, C.L.Parsely and S.J. Wilson have proposed the Detection of Central Respiratory Events using Pulse Transit Time in Infants. This is used to determine the capability of PTT to differentiate central respiratory events from tidal breathing. PTT is a valuable non invoice technique to monitor central apneic events in sleeping infants. PTT is sensitive to monitor the marginal Blood Pressure fluctuations during the tidal breathing [2].

In 2006, Peter Osterreicher has designed the Smart Baby Vest for Monitoring of Infants.

Revised Manuscript Received on February 05, 2020.

* Correspondence Author

Agnes Shiny Rachel, Assistant Professor, Department of ECE, Sri Krishna College of Technology, Coimbatore, India.

Pavithra M., Department of ECE, Sri Krishna College of Technology, Coimbatore, India.

Gokul kumar R., Department of ECE, Sri Krishna College of Technology, Coimbatore, India.

Lokesh N. S., Department of ECE, Sri Krishna College of Technology, Coimbatore, India.

(C) The Authors. Published by Blue Eyes Intelligence Engineering and Sciences Publication (BEIESP). This is an open access article under the CC BY-NC-ND license (http://creativecommons.org/licenses/by-nc-nd/4.0/)
It contains sensor for detecting respiration rate, pulse, temperature and humidity for continuous monitoring of infants under clinical and home conditions. When infants stop breathing, Zigbee is used to transmit the warning to the parents [3]. This can be designed as garments. In 2007, Yves Rimet and Yves Brusquet has proposed the paper on Surveillance of Infants at the Risk of Apparent Life threatening events with the BBA Bootle shoe.

The specially designed BBA shoes for infants consist of sensors, electronics and power supply. The sensor in shoes senses the pulse rate, temperature and the infants position in the cradle. It is also used to detect the prone position by an integrated 3-axes accelerometer. The ability of BBA Bootle system is to memorize alarm-triggering events, so that, they can be analysed[4]. In 2010, Ziganshin E.G. and Numerov has proposed the UWB Baby Monitoring. Baby Monitoring has remote contactless monitoring of heart rate and respiratory events of infants. It is called as Baby Sleep Guard (BSG) and it does not provide any useless information during the baby sleep. BSG is also equipped with temperature and pulse sensor to prevent SIDS [5]. In 2011, Shruti Priya Iyar has designed Low Cost Infant Monitoring and Communication System. It is used to measure the body temperature. If the body temperature exceeds 38 degree Celsius, it will send an SMS to the parents through GSM technology [6]. In 2013, MIT has introduced an 'Eulerian Magnification' technique. In this, they take a video as an input as standard sequence, spatial decomposition and temporal filtering to the frames [7]. In 2015, Divya Venkatramani proposed a device for Infant Monitoring Using the Wearable Computer. The system is used to monitor the infant by using wearable devices. The information is stored in a chip and it also sends warning to the parents [8]. In 2017, Dr. Tokunbo Ogunfunmi designed a Video Based Baby Monitoring System. The system has a light vision camera to observe the movement of the infant in the cradle. In this 'Eulerian Magnification' technique is used to amplify the subtle movement. It helps to compare the pixel color difference in frames for breathing detection in a recorded video of the baby. After finding the difference in breathing rate, it generates an alarm in the cradle [9]. In 2018, Toshaljeet kaur proposed the baby monitoring room prototype model using IOT. In this, the whole room is set to sense the activity of the infant. All the home appliances become connected to internet, which make them smart device as they can work by their own. It checks whether the baby is sleeping or not and also checks if the room condition is favourable for the baby or not. It uses WI-FI and Bluetooth technology for short range communications [10].

In 2019, Nedheela. N. Nazar designed a smart cradle using IOT. The smart cradle consists of temperature and wetness sensor which is used to detect the temperature and wetness of the baby.

Published By: 
If it increases beyond a particular range, a message will send to the parents with the help of blynk server. It also contains the MIC in the cradle. If the baby cries, the cradle will start swinging with the help of a dc motor and a song will be played through the speaker [11]. The proposed system of ours aims to measure the breathing rate and temperature of the infant. If there is any deviation in the threshold range, it generates an alarm in the cradle and sends an SMS to the parents with a video recording. The cloud technology is used to store the video of the infant. This will enable the physicians to identify the reason behind the elevation of breath rate and temperature and hence administer proper treatment. By this, we can reduce the mortality of the child due to SIDS.

\section{PROPOSED FRAME WORK}

The Block Diagram of the proposed system is shown in Fig.1. The hardware is chosen in consistence with the proposed framework. The program required for the automation is written using Python language which is later cast off onto the Raspberry pi 3 hardware.

\section{BLOCK DIAGRAM}

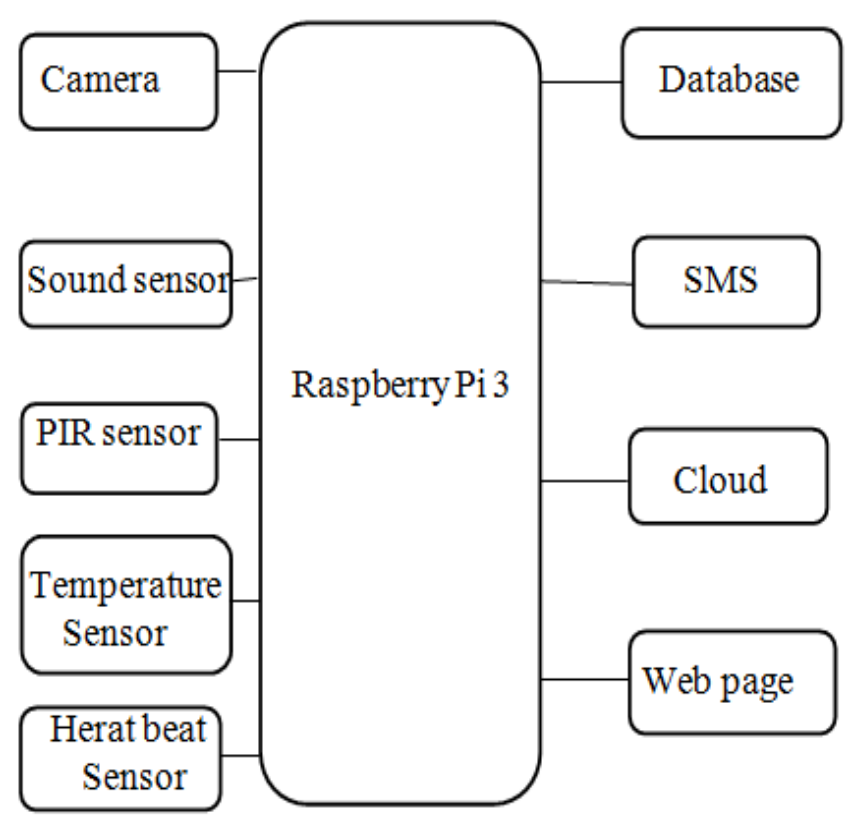

Fig. 1. Block Diagram of Proposed Architecture

\section{A. Heart Beat Sensor:}

Heart beat sensor is designed to measure the pulse rate of the infant. It operates at a voltage range of $3.3 \mathrm{~V}$ or $5 \mathrm{~V}$ with a current of $4 \mathrm{~mA}$. It is also used in mobile application. It includes an amplification and cancellation circuit. The LED in the sensor is placed above a vein of the infant's body parts like earlobes or fingers. Transparent strikers are used in the sensor to protect it from sweaty earlobes and fingers. After LED is placed on the body, it starts emitting light. When the heart pumps, there is a blood flow in the veins. With this blood flow this sensor measures the heart rate. The Raspberry pi does not read the analog input. So, ADC is used to convert an analog input to digital. The positive pin in the sensor is connected to $3.3 \mathrm{~V}$ from the Raspberry pi and the data pin is connected to ADC and the negative pin is connected to ground. The measured digital output from ADC is connected to Pi directly to measure the pulse (Beats Per Minute) rate.
When the pulse exceeds the threshold (180 BPM) range, the Raspberry Pi generates the SMS and sends it to the parents and guardian.

The normal range of pulse rate for people of all ages during sleep and when alert are tabulated below in Table 1.

TABLE 1

\begin{tabular}{|l|l|l|l|}
\hline $\begin{array}{l}\text { S. } \\
\text { No. }\end{array}$ & Age group & $\begin{array}{l}\text { Pulse rate } \\
\text { when alert }\end{array}$ & $\begin{array}{l}\text { Pulse rate } \\
\text { in sleep }\end{array}$ \\
\hline 1 & $\begin{array}{l}\text { Infant (1 month }-1 \\
\text { year) }\end{array}$ & $100-150$ & $90-160$ \\
\hline 2 & $\begin{array}{l}\text { Toddler(1 year }-2 \\
\text { years) }\end{array}$ & $70-110$ & $80-120$ \\
\hline 3 & $\begin{array}{l}\text { Preschool(3years-5 } \\
\text { years) }\end{array}$ & $65-110$ & $65-100$ \\
\hline 4 & $\begin{array}{l}\text { School age(6 years - } \\
11 \text { years) }\end{array}$ & $60-95$ & $58-90$ \\
\hline
\end{tabular}

Of all the tabulated values, the proposed system which aims at scaling down the deaths reported of SIDS, works to monitor the infants who lie in the age group of one month to one year.

\section{B. Temperature sensor:}

Temperature sensor (LM35) is used to measure the temperature of the infants. It operates at the voltage between $3 \mathrm{~V}$ to $5 \mathrm{~V}$. LM35 series are the precision integrated-circuit temperature sensor. The sensor value ranges from (-50 to 150) degree Celsius. It provides a linear response. The linear output voltage is proportional to Celsius. The positive pin is connected to $5 \mathrm{~V}$ from raspberry pi and the data pin is connected to ADC and the negative pin is connected to ground. The ADC stores 10 bit data. The analog output from LM35 is connected to ADC. It converts an analog input to digital output. The ADC is connected to Raspberry pi. When temperature exceeds 36 degree Celsius, Raspberry pi generates an SMS and sends to the parents or guardian. With this, SIDS can be prevented.

The normal and the fever temperature of all age groups of people are tabulated below in table 2 .

TABLE 2

\begin{tabular}{|c|c|c|c|}
\hline $\begin{array}{l}\text { S. } \\
\text { No. }\end{array}$ & Age Group & $\begin{array}{c}\text { Normal Body } \\
\text { Temperature } \\
\text { (degree Celsius) }\end{array}$ & $\begin{array}{c}\text { Fever } \\
\text { Temperature } \\
\text { (degree } \\
\text { Celsius) } \\
\end{array}$ \\
\hline 1 & (0-1)month & 32.4 & 36 \\
\hline 2 & (1-3) month & 34.8 & 38 \\
\hline 3 & $\begin{array}{c}3 \text { month }-3 \\
\text { year }\end{array}$ & 36 & 39 \\
\hline 4 & $\begin{array}{l}\text { Greater than } 3 \\
\text { year }\end{array}$ & 37 & 40 \\
\hline
\end{tabular}

Of all the tabulated value, the proposed system aims to scale down the death caused by SIDS for the infants whose age falls between 1 month and 1 year. 


\section{Pir sensor:}

PIR sensor is a kind of motion detection sensor. Passive Infrared sensor senses the IR radiation from the human body. When PIR sensor detects IR radiation, it starts the web camera.

It is made up of pyro-electric sensor, which detects the level of IR radiation from the human body. The sensing ranges from $5 \mathrm{~m}$ to $12 \mathrm{~m}$. It is very small, inexpensive, easy to use and does'nt wear out. It is also used in security system. In SIDS prevention system, the PIR sensor is placed in the cradle. The PIR sensor will turn ON the web camera, when it detects the infrared radiation from the infant. The range of infrared radiation from human body is less than the visible light. The webcam captures all the motion of the infant and the information will be store in the cloud. When the baby is out of the cradle, PIR sensor will not detect the IR radiation. So, it will turn off the webcam. By this, it will reduce the power consumption and memory consumption in the cloud.

\section{Sound sensor:}

LM393 microphone sound sensor is used to detect any audio around the surroundings. A sound sensor will detect the sound intensity. It will generate an alarm, if the sound intensity is above a certain threshold. The microphone sensitive range is about (52-48) $\mathrm{db}$. The signal to noise ratio (SNR) is 54db. Sound sensor (LM393) produces both analog and digital output. The raspberry pi does not support analog signal, the digital output is directly connected to the Raspberry pi to eliminate the ADC convertor. The positive pin is connected to the $5 \mathrm{~V}$ power supply and the negative pin is grounded. The digital output pin is directly connected to the USB port in $\mathrm{Pi}$. The sound sensor detects the cry sound of the infant continuously and sends a digital output to the Pi. If the digital value exceeds the threshold value, it will generate an alarm in the cradle.

\section{E. Camera:}

Camera module is used to capture the picture and the video of the surroundings. The Raspberry pi camera V1 module is used in the proposed model. It is capable to store $2592 * 1944$ pixel image and also supports to capture $640 * 480$ pixel video. The pixel range of camera module V1 is 5 mega pixel. The focal length is $3.6 \mathrm{~mm}$. This camera works with all the models of Raspberry pi. The camera is directly interfaced with Raspberry pi. In the proposed system, the camera module is placed in the cradle. The camera is turned ON, when the PIR sensor detects the IR radiation. After that, it captures all the movements of infant in the cradle. It will be stored in the cloud for future purpose. The stored video in the camera be viewed by the doctors after the authentication from the parents. With this the proposed system helps to reduce the mortality of the infants due to SIDS.

\section{F. Raspberry pi:}

Raspberry $\mathrm{Pi}$ is a series of credit card sized single computer. It has ability to do many task as the computer. It is used in many applications like games, word processing and automation. It provides a set of GPIO (General Purpose Input Output) pins that allows controlling electronic computers and it is a very cheap computer. The Raspberry pi is of two models, they are Model A and Model B. The difference between model A and model B is USB port. Model B contain Ethernet port but Model A doesn't have it. It also comprises of memory (RAM), processor, GPIO and the SD flash

memory card and the WIFI adaptor. In SIDS prevention, Pi is used to automate the cradle. The Raspberry Pi 3 (Model B) is used here for the advancement. The automation is done by using Python language. The information from all the sensors is sent to the Raspberry Pi. If the actual value from the sensor which is cast onto the Raspberry pi exceeds the threshold value, it will generate the SMS and send to the parents or guardian. With this, the proposed system reduces the death of infants due to SIDS.

\section{G. Gsm module:}

GSM module is digital cellular technology. It is a chip which is used to establish communication between a mobile device and the microcontroller or computer. It is also used for transmitting mobile voice and the data service. It operates at the frequency bands of $850 \mathrm{MHz}, 900 \mathrm{MHz}, 1800 \mathrm{MHz}$ and 1900 MHz. GSM uses a Time Division Multiple Access (TDMA) technology for communication. It consists of mobile station, base station module and the network subsystem. It provides SMS, high quality speech. It also provides encryption to give more security. In the proposed system, we use GSM module to send an SMS to the parents or guardian of the infants. GSM module is powered by $5 \mathrm{~V}$ from the Raspberry pi. The transmitter pin in GSM module is connected to receiver of $\mathrm{Pi}$ and the receiver pin in GSM module is connected to transmitter pin in Pi. After that, threshold value in $\mathrm{Pi}$ is compared with the actual value from the connected sensor. If the actual value exceeds the threshold value, Pi will send an information to the GSM module. The GSM module sends an SMS to the parents mobile to indicate the infant movement, according to the program. With this, we can control the mortality of the infant.

\section{H. Cloud technology:}

Cloud computing is an operating technology.. It has a large file storage and backup facility. In the proposed system, we use a cloud technology along with machine learning algorithm. The cloud technology is used to store the video of the infant which is captured by webcam in Raspberry pi. Machine learning algorithm is used to analyze the input data to predict output values. The webcam captures the movement of the infant and it is stored in the cloud. The Homo-morphic algorithm is used to provide the security. It is an encryption algorithm and provides remarkable computation facility for encrypting data and return encryption result. It solves security and confidential issues. It solves the threat while transferring data between the doctor and parents. It hides plain text from service provider and operates only on cipher text. After receiving an SMS and getting the authentication from parents, the video in the cloud is verified. According to the movement of infants, the first aid to the parents is informed through phone.

\section{RESULT}

In this section, the result of Baby Monitoring device for SIDS prevention is discussed. Figure b. shows the connection of the proposed system. The temperature sensor, heart beat sensor and the sound sensor is connected to Raspberry pi. The measured value is sent to the raspberry pi. 


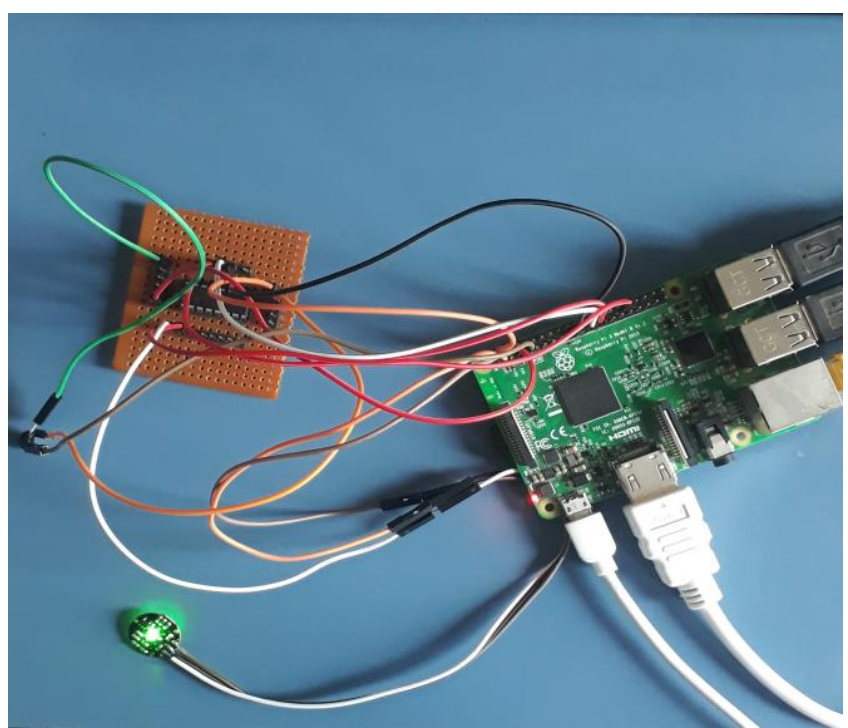

Fig 2. Connection of the proposed system.

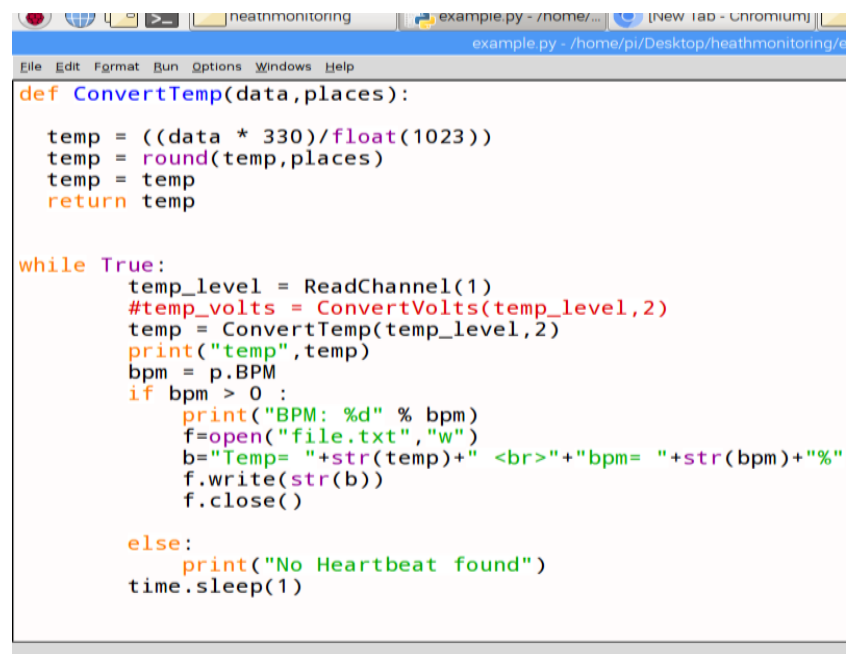

Fig. 3 Coding for the proposed system.

Fig d. shows the measured value of the temperature and heartbeat. If the temperature exceeds the threshold value (36 degree Celsius) sends an SMS.

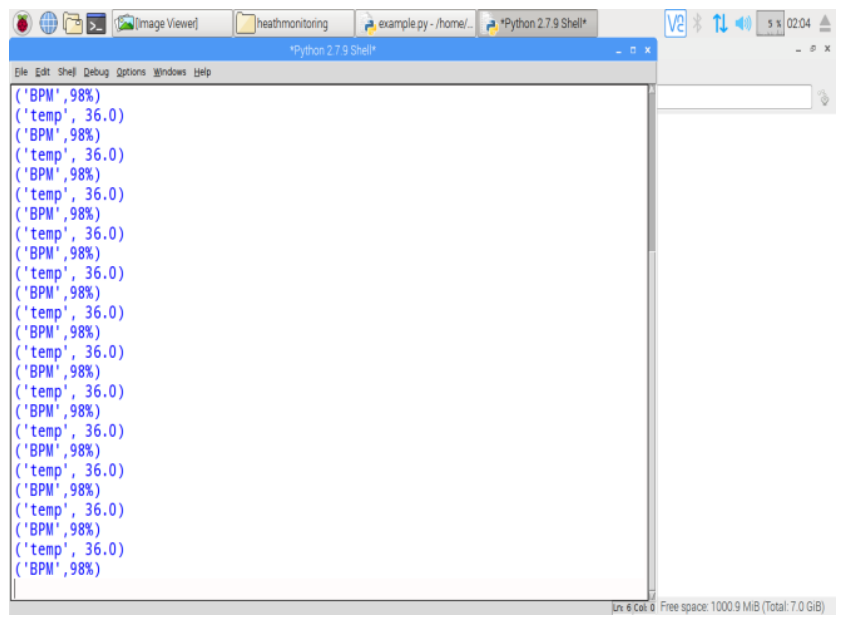

Fig. 4. Measurement of temperature and pressure.

Figure e. displays the temperature and heart beat in the local webpages. It doesn't require an internet, so we can easily monitor the infant. It helps to prevent the infant from SIDS.

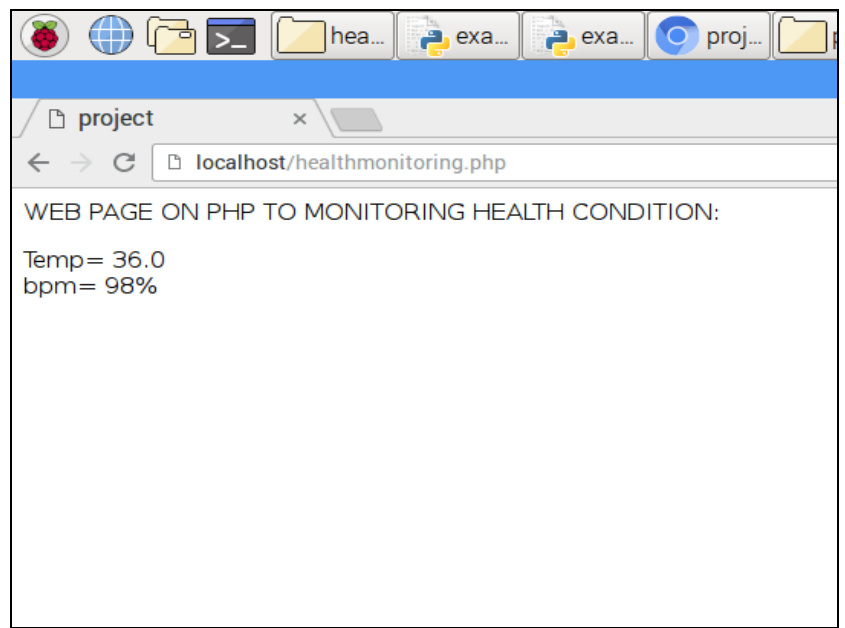

Fig. 5. Displaying the temperature and heart beat in webpage.

If the temperature or pulse rate exceeds the threshold, it will send an SMS. The parents of the infant will send an authentication to the doctor. After getting the authentication, the doctor check the video in the cloud. By seeing the video, they send the first aid method to the parents. With this we can reduce the mortality of the infant.

\section{CONCLUSION}

Baby monitoring for SIDS prevention using IOT is designed to prevent the increasing death rate among infants by measuring the temperature, pressure and detecting the cry of the infant. The camera and PIR sensor is placed on the cradle. When the baby is present in the cradle, the PIR sensor will detect the infant and will start the camera. The temperature sensor senses the temperature. If the temperature exceeds the threshold of temperature 36 degree Celsius, it will send an SMS to the parents or guardian. The heart beat sensor measures the BPM. If the pulse rate exceeds the threshold of 150 BPM, it will send an SMS to parents or guardian. The camera continuously captures the video and it will be stored in the cloud. After getting the authentication from parents, the doctor could see the video in the cloud. By this, the doctor would identify the problem of the infant and will send the first-aid information to the parents/caretaker in the vicinity. With this proposed system, mortality of the infants due to SIDS can be greatly reduced.

\section{REFERENCE}

1. Waheb A. Jabbar, Saidatul N. I. S. Hamid, Akram A. Almohammedi Roshahliza M. Ramli, And Mohammed A. H. Ali - "IoT-BBMS Internet of Things-Based Baby Monitoring System for Smart Cradle"IEEE - Volume 7, July - 2019.

2. Mohsina Mohamed Kabeer, Nedheela N Nazar, Navami Krishna U A, Nighila Ashok and Shasna M A - "Infant Cradle Monitoring System using IOT" - IJARCCE - Volume 8, April - 2018.

3. Kyle Takeuchi, Dr. Tokunbo Ogunfunmi, Shivakumar Mathapathi and Xiaoting LIU - "Video based baby monitoring SIDS prevention" IEEE -2017.

4. Mohit Kumar, Mrs.Suryakala - "Temperature control and monitoring of incubator using IOT" - IJETCSE - Volume 12- Issue 1 - May 2016.

5. Aaishwarya Jadhav, Mr. Gaurav Khadse, Jaikumar Ambekar, Kranti Dive, Shubham Wadzirkar, Mr. Sonit Sharma and Divya Venkatramani - "Infant Monitoring using wearable monitoring" IJETR -Volume 3, Issue 11, 2015.

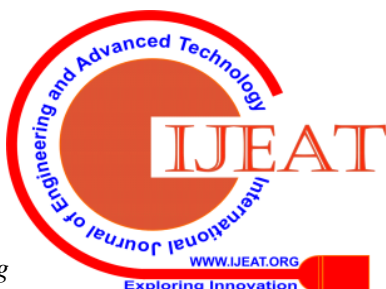


6. Savita P. Patil and Manisha R. Mhetre - "Intelligent Baby Monitoring"-ITSI-TEEE- Volume 2, Issue 1, 2014.

7. Adrian David Cheok, Ajith Perakum Madurapperuma, Chen Lihui, Elham Saadatian, Gopalakrishnakone Ponnampalam, Nii Hideaki, Owen Noel Newton Fernando, Shruti Priya Iyer and Zubair Amin "Low cost Infant Monitoring and communicating system" - IEEE 2011.

8. Numerov M. A., 3 Vygolov S. A. and Ziganshin E.G. - "UWB Baby Monitoring" -IEEE - page no. 159 - 161, September, 2010.

9. Caroline Rambaud, Christian Dageville, Christian Terlaud, Dominique Ronayette, Eric Mallet, Jean-Luc Weber, Jérôme Silve, Larissa I.Netchiporouk, Marc Lubrano, Olivier Lerda, Yves Brusquet and Yves Rimet,- "Surveillance of infants at risk of apparent life threatening events (ALTE) with the BBA bootee: a wearable multi-parameter monitor" - IEEE - page no. 4997- 5000, August, 2007.

10. Carsten Linti, Hansjurgen Horter, Heinrich Planck and Peter Osterreicher, "Sensory baby vest for the monitoring of infants" - IEEE $-2006$.

11. C. L. Parsley, D. M. Cooper, J. Y. A. Foo, S. J. Wilson, G. R. Williams and M. Harris - "Detection of Central Respiratory Events Using Pulse Transit Time in Infants" - IEEE - September, 2005.

12. Angelika Stellzig-Eisenhauer, Arnon Cohen, Dror Lederman, Ehud'Zmora, Kathleen Wermke ,and Stephanie Ha schild - "On the Use of Hidden Markov Models in Infants' Cry Classification" - IEEE page no. 350 to $352-2002$.

\section{AUTHORS PROFILE}

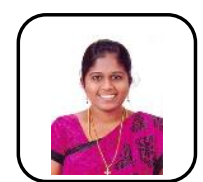

Agnes Shiny Rachel, ME,(PhD) is working as Assistant Professor (ECE) in Sri Krishna College of Technology, Coimbatore. She has an academic experience of 5 years. Her area of interest is VLSI sytems. She has published her papers in 6 international journals .

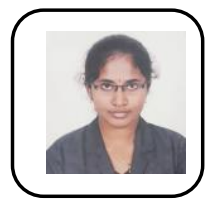

Pavithra M., is studying an Electronics and Communication Engineering in Sri Krishna college of Technology, Coimbatore. Her area of interest is Embedded system.

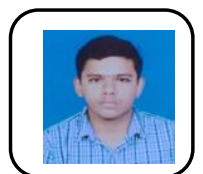

Gokul Kumar R., is studying an Electronics and Communication Engineering in Sri Krishna college of Technology, Coimbatore. His area of interest is Embedded system.

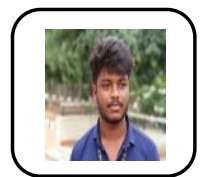

Lokesh N. S., is studying an Electronics and Communication Engineering in Sri Krishna college of Technology, Coimbatore. His area of interest is Embedded system. 